\title{
The Question of the Standard English Model in the Achievement of Universal Primary Education in Kenya
}

\author{
Martin C. Njoroge and Eunice A. Nyamasyo
}

\section{Introduction}

English and Kiswahili are the two key languages in Kenya. While Kiswahili is a national language, English is an official language and is actually the medium of instruction in Kenyan schools. The model of English used in Kenyan schools, even at the primary tier is claimed to be the British standard, particularly Received Pronunciation (RP) (Zuengler, 1982; Schmied, 1990, 1991; Kanyoro, 1991; Kioko and Muthwii 2001a, 2001b; 2002; 2004; Kembo-Sure, 2004). RP is the prestigious dialect that is spoken in the southern parts of Britain and it is used in the media and in the education system.

The assumption in Kenya is that at all the school tiers, the teachers, who are the learners' main linguistic models, have an excellent command of this yardstick of correctness and appropriateness with regard to pronunciation, grammar and lexis and that such teachers can teach the said variety. This assumption presupposes that teachers in Kenya will use similar linguistic forms to those that a British standard speaker uses in England despite their regional and socio-cultural differences (Kioko and Muthwii, 2004). But is this indeed the case? Is this what happens on the ground? A teacher's language use will in a great way influence the quality of the learner's language and will have a bearing on the learner's linguistic competence. Are the teachers presenting to their learners forms similar to RPs? What does the variability observed imply to Kenya's language-in-education policy? Determination of the exact model that learners are being presented with is paramount if achievement of quality education by 2015 is to be realised.

The second Millennium Development Goal targets at achievement of universal primary education by the year 2015 because better education is fundamental to the prospects of a country's economic and social development and the end of world poverty. In the achievement of this goal, every country must ensure that all boys and girls complete a full course of primary schooling. Basically, the major goals of primary education worldwide are achieving basic literacy and numeracy amongst all the pupils, as well as establishing critical foundations in such disciplines as science, geography and history.

Kenya's passion for education is well documented (Mbaabu, 1996). With free primary education policy put in place by the government in January 2003, there has been a tremendous increase in pupil enrolment in schools. Since the introduction of free primary education, an extra 2 million children are now accessing primary education (http://www.dfid.gov.uk). This increase means that the existing facilities and resources are really overstretched. Cases are reported where a single teacher handles over 100 pupils in a classroom. Despite the many challenges facing the implementation of this 
programme in the Kenyan school, efforts must be made to ensure that all children remain in school and receive a high quality education.

Kenya's Ministry of Education has implemented the Kenya Education Sector Support Programme, the roadmap to Universal Primary Education. The Ministry is addressing provision of books, teacher training, water and sanitation facilities and rehabilitation of existing classrooms and putting up of new ones. But other issues such as languagein-education policy and the use of ICT in education, which are equally important, have as yet to be fully addressed. For example, the revised English syllabus used in Kenyan schools state that the reference point to be used in teaching English is the commonwealth variety derived from British Standard English. Which is this standard? What is this commonwealth variety? Do the teachers use this variety in their teaching?

\section{Evidence on the ground}

A PhD research done by Njoroge (2006) set out to identify and describe both phonological and grammatical variations in the English spoken by teachers at primary school level in Kenya; determine how these variations depart from the British standard variety; correlate the linguistic variation observed with the social variables of ethnicity, gender, educational level and rural-urban dichotomy; and discuss the implications of the emergent sociolinguistic patterns for pedagogy in Kenya.

To achieve the aims of the study, data was collected from teachers in the rural areas of Bomet, Siaya and Thika districts and from Nairobi area, an urban setting. Judgemental sampling method and the social network approach guided me in choosing the required study sample. Classroom interactions were tape-recorded to obtain the language data and a questionnaire was used to elicit bio-data and information about educational qualifications and schools attended. In data collection, analysis, interpretation and discussion, we were guided by the Labovian Language Variation Theory. For the identification and description of the linguistic variations, description of the British Standard English as outlined in Roach (1998) and Wells (1982) for phonology and in Quirk et al. (1985) for grammar were used as reference points.

Njoroge (2006) observes that the English spoken by teachers in primary schools in Kenya vary significantly from the British standard variety, the model that is supposed to be the norm of correctness in Kenyan schools (Kioko and Muthwii, 2001). This is noted mostly in the phonological variations, with some cutting across all the social variables focused on in the study; for example, variations are noted in the use of the labio-dental fricatives [f] and [v]; approximants [r] and [1]; the alveolar fricatives [s] and $[\mathrm{z}]$; the velar plosives $[\mathrm{k}]$ and $[\mathrm{g}]$ and the inter-dental fricatives $[\mathrm{q}]$ and $[\mathrm{t}]$. Grammatical variations were also noted in the use of the article, preposition, subject verb agreement and pronouns. 


\section{Illustrations:}

\section{(A) Phonological}

(a) That word is [+1]ealise. Class say [+1]ealise. I want those who have not $[+1]$ ead to $[+1]$ ead. $\mathbf{M a}[+1] \mathbf{y}$ please $[+1]$ ead. There are questions $\mathbf{f}[+1]$ om the sto $[+1] \mathbf{y}$ and we cannot be able to answer those questions unless we [+1]ead again and understand it. Which animals do we keep according to the sto[+1]y? (KIRMG 2).

(b) We talk of [+1]eally when something is ve[+1]y small and another ve[+1]y big. A cheetah can [+1] un ve[+1]y fast. The coconut $\mathbf{t}[+1]$ ee is [+1]eally tall. Gatimu is $[+1]$ eally clever. Mangoes are quite sweet. So we can say mangoes are quite sweet... They are not ve[+1]y sweet, isn't it?... The black $\mathrm{d}[+1]$ ess is $[+1]$ eally expensive. What about the $\mathrm{g}[+1]$ een $\mathrm{d}[+1]$ ess?... He was [+1]ather disappointed. He was not fe[+1]y pleased... as we had said earlier, adjectives desc[+1]ibe a noun. (KIRMNG 5)

In a number of instances where the approximant $[\mathrm{r}]$ is expected in the RP, the lateral approximant is used as examples in (a and b) show. For instance, the highlighted letters in the following words, which were supposed to be articulated with the approximant [r], were produced with a lateral approximant [1]: writing, porridge, very, removing, correct and serious. Consequently, the words very [veri] and correct [kƯrekt] are articulated as [veli] and [këlekt] in the study data. In addition, variation was noted in the use of voiced and voiceless labio-dental fricatives as in the following examples.

(c) What are [+f]erbs? When you were in standard four you learnt about [+f]erbs. Sidiyo? And what do you say about $[+f]$ erbs? What are they? What are the [+]ferbs? What do you understand by the word [+f]erbs? If you look at our book page eighty fi[+f]le write for me at least fi[+f]e sentences using helping $[+\mathbf{f}]$ erbs, ama. You have realized the [+f]isitor we are ha[+f]ing? (KIRFG 4)

Another phonological variation observed was in the use of bilabial plosives [p] and [b] as in the following examples.

(d) Once there was a [+p]ig lion, staying in a forest... he tried his $[+p]$ est to $[+p]$ reak the net, [+p]ut he couldn't so the lion struggled. So, he used his teeth to cut the net and the lion was free... you can see some [+p]ody who is very rich... the lion was just walking [+p]oastfully (KARFNG 40)

(e) Yes when the [+p]ell rings.. Yes a few days ago, you drew a [+p]icycle and you la[+p]elled many parts of the $[+$ p]icycle...Say a $[+$ p]ottle to carry milk... A person who works who $[+$ p]uilds a house is called a $[+$ p] uilder person who works in a li $[+$ p]rary is a li $[+$ p]rarian. $[+p]$ roadcaster works in a newsroom. A [+p]utcher works in a $[+\mathbf{p}]$ utchery. The cashier works in a $[+\mathbf{p}]$ ank. The dog was given a [+p]one... (KAUMNG 46) 
In example (e), the word bell is articulated with sound [p] thus producing [pel]. Similarly, the words bank, [bæKk] and bone [bÙun] are articulated as [pæKk] and [pon] respectively. Likewise, the word labelled [leibld] is articulated in the study data as [leipëd] instead of [leibld] in RP. It is worth noting that this particular variant occurs in word-initial and word-medial positions.

(e) When you are introduced to a stranger by a friend, we $\mathbf{u}[+\mathbf{s}] \mathbf{u a l l y}$ say " it is a plea[+s]ure to meet you. (LRMNG 22)

(f) You must have learnt this in science. A thermometer is used to mea[+s]ure what? Can we all say to mea[+s]ure temperature. (LRFNG 24)

(h) Who can tell us why they visit towns? You don't know? Yes, what did you say? For lei[+]sure? Yes we may visit just for lei[+s]ure. (LRFNG 32)

In the examples in $(\mathrm{f}, \mathrm{g}, \mathrm{h})$, the voiceless alveolar fricative [s] is used in the highlighted words, instead of the expected voiced post-alveolar fricative ['] in RP. For instance in (g), the word measure [me'Ù] is articulated in the study data as [mesa]. The use of variant [s] instead of the voiced post-alveolar fricative seems to be influenced by mismatch between orthography and pronunciation. For example, in the highlighted words in (f, g and h), the grapheme $<$ s $>$ is used in orthography but in pronunciation, the voiced post-alveolar fricative ['] is the expected sound in RP.

What can be noted from the identification and description of the variation that relates to the articulation of various phonological variables is that different variants relate to a number of features such as voicing, place and manner of articulation. For example, in the articulation of fricatives, these include differences in voicing. For instance, there are cases where a voiced variant $[\mathbf{z}]$ is used instead of the voiceless variant [s] thus contributing to variability.

There is also variability related to differences in place of articulation, for example, in the articulation of the alveolar fricative [s] instead of the post-alveolar fricative [ + "] or the use of a dentalised alveolar stop instead of the expected voiceless alveolar plosive [t]. Finally, there is also variability resulting from differences in manner of articulation. These include examples in which variant $\left[\mathbf{t}+{ }^{\prime \prime}\right]$, an affricate, is used instead of a fricative [+"].

\section{B. Grammatical}

(a) (^of indef.art. a) rat is a very small animal and (^of indef.art.a) lion is a big animal and is a big animal. So [^of def.art. the] lion, no [^of def.art. the] rat said...so [^of def.art. the] rat ran away... so [^of def.art. the] rat lived in hole. We have big animals like [^ ${ }^{\wedge}$ of def.art. the] elephant, [^of def.art. the] lion and so on. [^of def.art. the] elephant is bigger than [^of def.art. the] rhino. What do you think? (KARFNG 40)

In the examples highlighted in (a), there is the omission of either the definite article the and the indefinite articles $\mathbf{a}$ and an. For example, the indefinite article $\mathbf{a}$ is needed 
to indicate that the noun 'rat' is a count noun and that it is being mentioned for the first time in the discourse. The second time the noun 'rat' is mentioned means that it has a direct anaphoric reference and, therefore, it requires that the definite article the be used to indicate that the two nouns have co-reference relations. However, in the study data, the article is omitted as example (a) shows. Another phenomenon observed was pronoun copying as in the following example.

(b) Soi's grandmother she took him to the bus stop because Soi had to leave early in the morning. The grandmother she feared that Soi would be attacked. It was still very dark...Think about what happens in a harbour, like Kenya's Kilindini harbour. Somebody? Very good. The containers they were being lifted up (KIRMG 2)

In the examples in (b), the occurrence of a pronoun immediately after the noun phrases that function as the subject in the sentences can be noted. In so doing, it becomes as though there is occurrence of double subjects within the same sentence, though these two subjects have the same co-referent. Such a combination is hardly used in the British Standard English, unlike in most of the African languages

The finding shows that there is a discrepancy between the theoretical norm of the English language used in education (RP) and the actual language behaviour and this needs to be addressed. The study also revealed that the level of education contributes to a reduction of the variation from the standard forms. Further, the varieties of English spoken in Kenya seemed to form a hierarchy, with the less educated variety occupying the base while the educated variety is close to other native-speaker varieties.

There are two views regarding the use of English in non-native contexts: exonormative and endonormative standards (Platt et al., 1984). Should a country continue using standards that are native-speaker determined or standards that are locally determined? The use of standard variety is the norm of correctness in Kenyan schools, but as Njoroge (2006) observes, the teachers themselves have not fully acquired this norm. Given this sociolinguistic reality in education in Kenyan primary schools, it is almost impossible for the learner to keep in touch with the British Standard English because of lack of resources and overwhelming non-native input.

One can argue that the spoken English used by these teachers has interacted with the local ethnic languages thus varying from the British standard. This is one variety of English that learners in Kenyan primary schools are presented with in the classrooms by their teachers, their linguistic models. This indigenised variety is what Kenyans are in touch with (Kioko and Muthwii, 2001) and not the standard British variety as claimed in Zuengler (1982) and Schmied (1991). We can posit that the expectation by policy-makers of a native-like competence in English for the non-native teachers is an ideal and possibly cannot become a reality in Kenya, as shown by the findings in Njoroge (2006). 


\section{Lessons from other New Englishes contexts}

Users of English speak and write English differently and as an imported language in many countries, it has inevitably undergone local changes that have evolved into distinct and different varieties of the language. Linguists (Cheshire, 1991; Coelho, 1997 and Widdowson, 2003) now generally accept the existence of varieties of English different from the native speakers' varieties and there has been a growing interest in describing and codifying these non-native Englishes which Platt et al. (1984) refer to as 'New Englishes' and Kachru (1992) calls 'the English of the outer circle.'

Linguists such as Schmied (1991) and Bamgbose et al. (1995) study the varieties of English spoken in diverse contexts and have even come up with such techniques as assembling computer corpora such as the International Corpus of English (Nyamasyo, 1994). To describe such varieties, they use one of the native speakers' standard varieties as the point of reference. The majority of these studies use Britain's Received Pronunciation as a reference point. RP is the standard form of pronunciation in Britain and it is the accent that is associated with prestige in Britain.

In some no-native English speaking nations, a great deal of research has been undertaken with a view to describing the linguistic forms of the variety of English spoken by the citizens (Platt et al. 1984). In a number of countries, for instance India and Singapore, there has been an adoption of the localised variety of the English language in education. Linguists in such countries have identified and codified a local standard variety of English. Thus, we talk of Singaporean English, which today functions as the language of government, education and the media, having taken over from a previously supposed British standard variety.

Kandiah (1991) argues that while the norms governing the linguistic usage and behaviour in non-native contexts are certainly based originally on those of the native speaker, these norms have subsequently been influenced by their interaction with the local languages, as well as by the new contexts in which English has been used. Kandiah further adds that out of the original interaction between English and the local languages, there have emerged self-contained new systems that incorporate new elements, combinations and meanings.

In Nigeria, researchers such as Bamgbose (1982; 1995) and Bokamba (1984) have described what can be referred to as Nigerian English. Grammar books and dictionaries have been written and compiled so that teachers and other speakers of English in Nigeria may have some points of reference for a variety that is presently termed Nigerian English (Bamgbose et al., 1995).

Research into some of the non-native varieties, however, has lagged behind (KemboSure, 2004). One of the reasons highlighted for this lack of enthusiasm is the myth that the English taught in non-native contexts such as Kenya and Nigeria is the British standard (Totally Integrated Quality Education and Training, 1999). Another reason that is put forward is the fear that if a variety other than the native-speaker one is accepted as the appropriate model for education, it may degenerate into a very different 
language that will lack mutual intelligibility with other standard varieties. Third, there is the influence of the prescriptivists who analyse any deviation from the nativespeakers' varieties as errors (Kioko and Muthwii, 2001).

As Kioko and Muthwii (2001) observe, there has been some reluctance on the part of the language policy makers in non-native contexts to adopt the local forms of English as the official language (Banjo, 1995 and Kujore, 1995). Despite this reluctance, linguists observe that due to interaction with other languages in the environment, English has been made to acquire local social meaning distinct from those of the indigenous languages (Muthwii, 1994); it has also undergone structural changes at all linguistic levels and has been nativised. It is being adapted to the local or regional sociolinguistic conditions in which it finds itself. Hence, the English language as it is used, for example, in Kenya is bound to show variation from the variety spoken in Britain due to sociolinguistic differences.

\section{Which way forward?}

If Kenya is to achieve high quality primary education by 2015, there is need to ask what the future of English language use in Kenya should be, especially in education. There is need to address the issue of a more practical standard variety that should act as an appropriate yardstick in the use, teaching and learning of English in Kenyan schools. As it is now, the teacher is expected to use RP as a linguistic yardstick in pronunciation. But how many of them will articulate the word 'home' as the diphthongised [hÜum]? This points to the fact that there is a discrepancy between the actual behaviour and the theoretical norm in language in education in Kenya.

Should Kenyans import native English teachers and teacher supervisors, to be the reference for the teacher and the learner and also to act as agents of continuing education for the Kenyan teacher of English? As Kioko and Muthwii (2001:20) observe, this would be a very expensive option, considering the number of schools that Kenya has. Getting enough native English teachers to attend to all local needs will be an insurmountable hurdle. After all, the RP speakers are a minority, even in England (Kashina, 1994). As an export commodity, RP speakers are in short supply and can be recruited only at great expense; thus, it would not be economically viable to import them to Kenya.

Another option would be to send language teachers to native contexts to learn the standard forms. As Kioko and Muthwii (2001) suggest, Kenya can opt to regularly send some of the teachers of English for short courses in native-speaker contexts so that they can improve on both their pronunciation and grammar. This would provide an invaluable input for such teachers so that when they come back to Kenya, they will be appropriate linguistic models for their learners; they will be able to impart this ideal native speaker standard to the learners. However, this would be a very expensive venture which the country can hardly afford.

The third suggestion would be for educators and linguists in Kenya, together with native speakers of the British standard variety, to team up to study the way English is 
used in Kenya and publish on areas of discrepancy which would guide the teachers and learners alike. As Kioko and Muthwii (2001: 209) argue, such a measure would create a move that is not in line with other innovations in the democratisation and Africanisation of education in Kenya.

We concur with Kioko and Muthwii's (2001) view that the more realistic and prudent move would be to accept the sociolinguistic reality of English in Kenya and work out a new direction for its use in the education system. The socio-cultural circumstances of learning and using English cannot be ignored and this sociolinguistic reality should be taken into consideration when mapping out the practical model that should be used as the standard while teaching and using English in education in Kenya (KemboSure, 2004).

A detailed research into the educated Kenyan variety of English will need to be undertaken. It is after such a research that the educated Kenyan's variety of English can be adopted as the endonormative model and consequently used in the education system in Kenya. The external varieties of English need not be imposed as the standard and norms for teachers and learners in Kenya. As the findings in Njoroge (2006) reveal, teachers make use of some linguistic features that make their variety of English unique and distinct from the British standard variety, and it is this distinct and nativised variety that the learners interact with as they listen to their teachers in the classroom. As Kachru (1992) argues, the implications of the sociolinguistic reality of English language use around the world need to be recognised.

The dual role of English both as a national language and as an international language in Kenya should be borne in mind in policy-making and standard setting. We argue for the consideration of the sociolinguistic reality in which English finds itself in Kenya, so that a more practical norm of correctness that will be meaningful to the students and achievable by the teacher is adopted for use as a medium of instruction. Curriculum developers and educators need to address this issue of a practical and realistic model if Kenyan users of English are to avoid the dilemma that Rao (as cited in Ashcroft 1989: 61) talks about when he remarks that:

... The telling has not been easy. One has to convey in a language that is not one's own the spirit that is not one's own. One has to convey the various shades and omissions of a certain thought-movement that looks maltreated in an alien language... We are all instinctively bilingual, many of us writing in our own language and English... We cannot write like the English. We should not. We can write only as Indians.

The adoption of the local educated standard of English as the yardstick in Kenyan education system, which can replace the British standard, will not be easy and neither will it go unchallenged. Definitely, there are those Kenyans who feel that anything but the British standard is an error. They believe that there can never be a local standard even though their own speech and usage of English provide ample evidence of its existence. Such Kenyans would see the formal adoption of a non-native variety as contributing to language decay, careless usage, or loss of intelligibility among its users across cultures (Kioko and Muthwii, 2001). 
As Thiong'o (1986) puts it, there are those Kenyans at the top who will be furious at fellow Africans who mispronounce an English word but will laugh with pride at their own inability to speak a single correct sentence in their own language. He further adds that in some government offices, the ability to speak the Queen's English, exactly like an upper-class English man, is the sole criterion for employment and promotion. It seems that although the existence or evolution of a Kenyan variety of English can be generally recognised, there may not be much enthusiasm for its use in place of British English.

As Brumfit (1982: 89) aptly puts it, the best goal for the non-native speaker is the English of the most educated and articulate speakers of English in his or her own linguistic group. Though the educated Kenyan's variety of English has not been codified and put together, we see it as the most plausible medium of instruction and, indeed, of communication in the society. Since it will be close to the British standard, it will retain intelligibility with this variety. In addition, the two will be very similar in phonology (Okombo, 1986) though the educated Kenyan variety may have some differences in phonetic features as well as having certain lexical peculiarities. This variety would be socially acceptable and accessible to the users. Due to its similarity with the British standard, the educated Kenyan variety will definitely be internationally intelligible. We do not advocate for acceptance of errors that result from deficient language learning. Indeed the use of new Englishes such as Singaporean English and Nigerian English has been successful and, therefore, use of Kenyan English as the point of reference can work in Kenya.

Kembo-Sure (2004) suggests some relatively objective criteria to use to characterise a suitable local form. For example, it has been suggested that it must be internationally intelligible, locally acceptable, and culturally relevant. The greatest advantage with such a local model is that it is realistic: it is achievable by the learner; it is demonstrable by the teacher; and it is easy to identify with by the learners. At the moment, there is a mismatch between aims of teaching English in Kenya, the model to be used, and actual practice.

\section{Conclusion}

It is the thesis of this paper that standard English is no longer the preserve of native speaker contexts. The language has become diversified and it serves a whole range of different communities. Thus, the native speakers of the language can no longer presume to decide for all speakers of the language- including non-native speakerswhat counts as good, bad, acceptable or correct English. Due to this diversification of English, different standards inevitably have to emerge. After all, the non-native speakers hardly get opportunities to interact closely with native speakers and get a chance to acquire native-like phonology and grammar.

Appropriate pedagogy considers the way to prepare learners to be both global and local speakers of English so that they can feel at home in both international and national cultures. Speakers of English will, therefore, have to strike a balance between the national ethos and international functions of English. They should be able to continually renew and alter their variety to suit their socio-cultural surroundings. 
The question of the model of English to be used in the education system in Kenya, therefore, should not be ignored. If education is to be seen as a vital vehicle in national development, then a workable language policy in education, advocating for a practical and attainable model, is of paramount importance. As Kioko and Muthwii (2001) remark, it is only when the Kenyan standard is incorporated in the education process that language in education will be made more relevant and dynamic in Kenya. In so doing, the theoretical norm and actual language behaviour will show less discrepancy and achievement of quality primary education by learners will become a reality. Thus, Kenya should utilise her own brand of English if the language-in-education policy has to be practical and meaningful to learners and teachers.

\section{References}

Ashcroft, B., Griffiths, G. and Tiffin, M. (1989). The empire writes back: Theory and practice in post-colonial literatures. London: Routledge.

Bamgbose, A. (1982). "Standard Nigerian English: Issues of identification." In Kachru B. (ed.). The other tongue: English across cultures. Oxford:

Pergamon Press.

Bamgbose, A., Banjo, A. and Thomas, A. (eds.). (1995). New Englishes: A West African Perspective. Mosuro: The British Council.

Banjo, A. (1995). “On codifying Nigerian English: Research so far”. In Bamgbose. A. et al. (eds). New Englishes: A West African perspective.

Mosuro: The British Council.

Bokamba, E. (1984). “The fiction of the native speaker in L2 research.” In Alatis, J. E. (ed.). GURT on languages and linguistics, pp 243- 252. Washington: Georgetown University Press.

Brumfit, C. J. (1982). Communicative methodology in language teaching.

Cambridge: Cambridge University Press.

Cheshire, J. (ed.) (1991). English around the world: Sociolinguistic perspectives.

Cambridge: Cambridge University Press.

Coelho, G. (1997). "Anglo-Indian English: A nativised variety of Indian English". Language in Society 26 (4), 561-89.

DFID (2007). Focus on Africa. Retrieved March 27. Web site: http://www.dfid.gov.uk

Kachru, B. (ed.). (1992). The other tongue: English across cultures. Oxford: Pergamon Press.

Kandia, T. (1991). "South Asia." In Cheshire, J. (ed.). English around the world: Sociolinguistic perspectives. pp 271-287. Cambridge: Cambridge University Press. 
Kashina, K. (1994). "The dilemma of standard English in Zambia: Pedagogical, educational and socio-cultural considerations." Language, Culture and Curriculum, Vol. 7:1, Clevedon: Multilingual Matters.

Kembo, S. (2004). “Establishing national standard and English language curriculum change in Kenya." In Muthwii, M.J. and Kioko, A.N. (eds.). New language bearings in Africa: A fresh quest. Clevedon: Multilingual Matters.

Kenya Institute of Education (2002). Revised English syllabus for Kenya primary schools. Nairobi: Kenya Literature Bureau.

Kioko, A. and Muthwii, M. (2001). "The demands of a changing society: English in education in Kenya today." Language, Culture and Curriculum. Vol. 14:3, 201-213.

Kioko, A. and Muthwii, M. (2002). "Whose English in Kenyan schools? A case for a nativized Variety." In Chemi Chemi: International Journal of the Schools of Humanities and Social Sciences. Vol.2 No 1: 78-86.

Kioko, A. and Muthwii, M. (2004). "English Variety for the public domain in Kenya: Speakers attitudes and views". In Muthwii M. and Kioko, A (eds.). New Language Bearings in Africa: A Fresh Quest. Clevedon: Multilingual Matters.

Kujore, O. (1995). “Whose English?” In Bamgbose, A. et al. (eds). pp 367-380.

Muthwii, M. (1994). “Variability in language use: A study of Kalenjin speakers of English and Kiswahili in Kenya." Unpublished PhD Thesis, University of East Anglia, Norwich.

Njoroge, M. (2006). Linguistic variation in spoken English as used by teachers in Kenyan primary schools. Unpublished PhD thesis, Kenyatta University

Nyamasyo, E. (1994). "An analysis of the spelling errors in the written English of Kenyan pre-university students." Language, Culture and Curriculum, 7 (1), 79-92.

Okombo, O. D. (1986). The functional paradigm and Dholuo constituent order. Unpublished PhD Thesis, University of Nairobi.

Platt, J., Weber, H. and Lian. (1984). Singapore and Malaysia. Volume 4 in Varieties of English around the world. Amsterdam and Philadelphia: Benjamins.

Roach, P. (1998). English phonetics and phonology (2nd $e d)$. Cambridge:

Cambridge University Press.

Schmied, J. (1991a). English in Africa: An introduction. London: Longman. 
66 Martin C. Njoroge and Eunice A. Nyamasyo

TIQET(1999). Totally integrated quality education and training report of the commission of inquiry into the education system of Kenya. Nairobi: Government Printers.

Widdowson, H.G. (2003). Defining issues in English language teaching. Oxford: Oxford University Press.

Zuengler, J. (1982). “Kenyan English.” In Kachru, B. (ed.). The other tongue: English across cultures. Oxford: Pergamon Press. 